\title{
p53 immunodetection of liquid-based processed urinary samples helps to identify bladder tumours with a higher risk of progression
}

\author{
E Piaton $^{*, 1,2}$, J Faÿnel ${ }^{1,2}$, A Ruffion ${ }^{3}$, JG Lopez ${ }^{3}$, P Perrin ${ }^{3}$ and M Devonec ${ }^{3}$ \\ 'INSERM U.407, Université Claude Bernard Lyon I, Lyon, France; 'Laboratoire d'Anatomie et Cytologie Pathologiques, Hôpital Edouard Herriot, Lyon, \\ France; ${ }^{3}$ Senvice d'Urologie, Centre Hospitalier Lyon Sud, Pierre Bénite, France
}

p53 could help identify bladder tumour cases with a risk of progression from superficial to invasive disease. Semiautomatic, liquidbased cytology ( $\mathrm{LBC}$ ) techniques offer an opportunity to standardise molecular techniques. The aim of our study was to investigate whether LBC could improve p53 immunolabelling, and to assess whether urinary p53 could have a prognostic value. Immunoreactivity for p53 was studied in 198 urine samples after treatment with the Cytyc Thinprep ${ }^{\circledR}$ processor. After antigen retrieval, cells were labelled with a monoclonal antibody that recognises both wild-type and mutant form of the p53 protein (Clone DO-7, Dako), I/I000. Positivity for p53 was assessed in 17.2\% of the cases. High-grade (G3) tumours were positive in $74.1 \%$ of the cases. Comparatively, low-grade (GI-2) urothelial carcinomas were positive in $23.5 \%$ of the cases. During a median follow-up period of 26 months, recurrence was observed in $52.9 \%$ of the cases with p53 overexpression, and in only $10.9 \%$ of negative cases $(P<0.00 \mathrm{I})$. The progression rate was $35.3 \%$ of $p 53$-positive cases vs $5.5 \%$ of $p 53$-negative cases $(P<0.00 \mathrm{I})$. Progression-free survival was significantly shorter in patients with $p 53$ accumulation $(P=0.007)$. In a multivariate analysis stratified on grade and stage, $p 53$ was an independent predictor of overall survival $(P=0.042)$. The results show that using Thinprep ${ }^{\mathbb{R}} \mathrm{LBC}, \mathrm{p} 53$ immunolabelling of voided urothelial cells allows most high-grade tumours to be detected and may help identify cases with a higher risk of recurrence and progression.

British Journal of Cancer (2005) 93, 242-247. doi:I0.I038/sj.bjc.6602684 www.bjcancer.com

Published online 5 July 2005

(c) 2005 Cancer Research UK

Keywords: p53; progression; urothelial carcinoma; liquid-based cytology

About $70 \%$ of superficial (TNM stage $\mathrm{pTa}-1$ ) bladder urothelial carcinomas will recur in the 5 years following transurethral resection (TUR), and 10-20\% will progress to muscle invasion (Saad et al, 2001). Patients treated for bladder cancer are therefore regularly followed up by cystoscopy and urinary cytology, but to date, no biological marker has gained wide acceptance in monitoring for tumour recurrence.

The p53 tumour suppressor gene is located on chromosome $17 \mathrm{p}$. Mutations and loss of heterozygosity ( $\mathrm{LOH}$ ) commonly induce p53 inactivation, which correlates with protein accumulation in the nuclei of tumour cells. Numerous studies have shown a clear correlation between p53 gene mutation and the tumour stage and grade of bladder tumours (Brandau and Böhle, 2001). Deletions of $17 p$ have been observed in more than $60 \%$ of patients with highgrade urothelial carcinomas, as well as in those who recur with muscle infiltration (Friedrich et al, 2001).

Since the initial data that reported a close correlation between p53 and prognosis, different and somewhat contradictory results have been published on tissue samples (Schmitz-Dräger et al, 2000).

* Correspondence: Dr E Piaton. Current address: Laboratoire d'Anatomie et Cytologie Pathologiques, Bâtiment I, Hôpital Edouard Herriot, 5, place d'Arsonval, 69437 Lyon Cedex 03, France;

E-mail: eric.piaton@chu-lyon.fr

Received I4 April 2005; revised 29 April 2005; accepted 6 June 2005; published online 5 July 2005
In cytological samples, p53 overexpression has been shown to have only $23.5 \%$ sensitivity and $75.0 \%$ specificity in detecting bladder tumours (Righi et al, 1997), but in other series, sequence analysis of voided urine specimens compared with tissue samples showed $84.2 \%$ sensitivity and $96.8 \%$ specificity (Prescott et al, 2001). For some authors, p53 overexpression in the urine could aid in predicting prognosis and in identifying cases that are likely to progress from superficial to invasive disease (Wolf et al, 2001).

Liquid-based cytology (LBC) automatons using filtration and thin-layer deposition of cells have been developed to replace cytocentrifugation methods, owing to cell recovery capabilities and better cell morphology. In the urine, the use of the Thinprep ${ }^{\mathbb{R}} 2000$ (Cytyc Corp., Boxborough, MA, USA) processor results in increased cellularity and marked reduction of debris, erythrocytes and crystals (Anagnostopoulou et al, 2000; Wright and Halford 2001; Piaton et al, 2002, 2004). Additionally, complementary techniques such as immunocytochemistry, DNA, RNA and protein molecular analysis can be successfully applied to Thinprep ${ }^{\mathbb{R}}$ processed samples, thus allowing the impact of biomarkers in a variety of human malignancies to be studied (Tisserand et al, 2003).

Considering this background, the present study was undertaken to investigate (1) whether LBC could help study p53 overexpression in voided urothelial cells and (2) whether p53 overexpression in the urine could be linked to increased risk of recurrence and/or infiltration in bladder tumour cases. 


\section{MATERIALS AND METHODS}

The study group consisted of 198 urine samples collected from consecutive patients viewed at consultation in two departments of Urology in Lyon, France. The study was approved by the regional ethics committees. Samples were obtained from male and female patients at least 18 years old, either consulting for symptoms possibly indicating bladder cancer (mainly gross haematuria) or being followed up after complete TUR or bacillus CalmetteGuérin (BCG) immunotherapy for bladder urothelial carcinoma at least 1 month earlier.

The results of cystoscopy were recorded as positive (papillary growth or abnormalities in flat mucosa strongly suspicious for CIS), suspicious (irregular appearance in flat mucosa, not otherwise specified) or negative. A TUR was performed in every case of papillary bladder lesion, and mucosal abnormalities suspicious for CIS were evaluated by biopsies. Histopathological characterisation and grading used was that of the WHO/ISUP 1998 classification (Epstein et al, 1998) and the staging was performed according to the UICC TNM classification.

Whether on initial presentation or during the follow-up, voided or cystoscopically obtained urine specimens were fixed with an equal volume of Carbowax (20\% polyethylene-glycol 1500 in $50 \%$ ethanol). The resulting samples were sent to the laboratory within $12 \mathrm{~h}$, together with clinical and cystoscopy data.

\section{Preparation of LBC slides}

After thorough homogenisation, the urine was processed according to the instructions for nonmucoid fluids provided by the manufacturer: samples were washed in phosphate-buffered saline and cells were resuspended in a Cytolyt ${ }^{\circledR}$ solution containing methanol, mucolytic and haemolytic agents. After $30 \mathrm{~min}$ at room temperature (RT), cells were centrifuged at $600 \mathrm{~g}$ for $10 \mathrm{~min}$ and resuspended in $45 \mathrm{ml}$ PreservCyt ${ }^{\mathbb{R}}$ solution before being treated.

The Thinprep ${ }^{\circledR} 2000$ automaton allows thin-layer cell preparations to be provided owing to a filtration process: after the TransCyt ${ }^{\circledR}$ filter has been plunged into the sample, it rotates at a high speed and facilitates cell and mucus dispersion. A vacuum is then applied to the filter, which collects cells on a $5 \mu \mathrm{m}$ porosity membrane. A software program allows a homogeneous deposition of cells until saturation. The TransCyt ${ }^{\mathrm{B}}$ filter is then inverted and a positive pressure allows cells to adhere to an electronegative slide. After insertion of another TransCyt ${ }^{\mathbb{R}}$ filter and of another slide, the whole procedure may be repeated until the entire sample has been treated.

In each case studied, the first slide obtained was stained with a hypochromic Papanicolaou procedure for cytopathologic evaluation. The second slide, when available, was used for p53 immunocytochemistry: cells were air-dried overnight, wrapped in metal foil and stored at $-20^{\circ} \mathrm{C}$.

\section{Urinary cytology and histopathology}

Cytopathologic analysis was performed at low- and high-power fields. Normal, inflammatory, reactive and degenerative conditions of the urothelial component, as described by previous studies (Murphy, 1990; Bastacky et al, 1999) were considered as negative, as well as urothelial atypias of undetermined significance. Specimens in which neoplastic cells were recognised (grade 3, grade 2 clearly identified in the pathology report, strong suspicion for papillary low-grade tumours based on architectural and nuclear abnormalities) were considered as positive for urothelial carcinoma (Bastacky et al, 1999).

Histopathological results were separated into three groups: one positive for high-grade urothelial lesions (pTIS and G3 tumours, whatever their stage) according to the criteria of the WHO/ISUP
1998 classification (Epstein et al, 1998), one consistent with low-grade papillary tumours (G1-2, pTa-1 tumours) and one negative.

\section{Immunostaining methods}

Before p53 immunolabelling, slides wrapped in metal foil were allowed to reach RT for $1 \mathrm{~h}$. Cells were then fixed in 95\% ethanol for $30 \mathrm{~min}$. In cases where low cellularity did not allow slides to be prepared for p53 immunostaining, Papanicolaou slides were destained in $70 \%$ ethanol overnight (destained slides - see Table 3), rinsed in $70 \%$ ethanol and then fixed in $95 \%$ ethanol for $30 \mathrm{~min}$.

Before labelling, slides were submitted to antigen retrieval for $15 \mathrm{~min}$ in $0.01 \mathrm{M}$ citrate buffer, $\mathrm{pH} 6.0$, at RT.

Cells were covered with a mouse monoclonal antibody to the p53 antigen (MoAb M 7001, clone DO-7, DAKO, Glostrup, Denmark) in a $1 / 1000$ dilution for $1 \mathrm{~h}$ at $\mathrm{RT}$ in a dark wet chamber. This antibody recognises both wild-type and mutant forms of the p53 protein. Slides were treated in the Ventana GenII $^{\circledR}$ processor (Ventana Medical Systems Inc., Tucson, AZ, USA) using a diaminobenzidine kit, and were slightly counterstained with Harris haematoxylin.

Negative controls were prepared by exclusion of the primary antibody. Known positive controls were included: slides were mixed with tissue sections of an archival bladder pT2 G3 urothelial carcinoma known for having 50-65\% p53 nuclear reactivity. The tissue specimen also served as a negative control after exclusion of the primary antibody. The expression of p53 was studied in the three groups of cases. A urine sample was considered as positive for p53 when at least 10 nuclei were stained, provided at least 100 urothelial cells could be counted in the whole specimen.

For p53 immunohistochemical detection, tissue samples from the 73 formalin-fixed, paraffin-embedded TUR and biopsy specimens were stained as follows: representative $5 \mu \mathrm{m}$ sections were deparaffinised and rehydrated. A pretreatment microwave heating in $10 \mathrm{~mm}$ citrate buffer, $\mathrm{pH}$ 6.0, was performed before incubation with the primary antibody.

The sections were treated with the D0-7 antibody at 1/50 dilution for $45 \mathrm{~min}$ at $\mathrm{RT}$. The reaction was revealed with the streptavidin-biotin complex method using an LSAB 2 Kit (DAKO S.A., Trappes Cedex, France). Tissue sections were considered as positive when at least $10 \%$ of nuclei were stained, whatever the intensity $(x-x x x)$.

\section{Analysis of data}

Time to recurrence was calculated from D0 (time of biopsies or TUR) to the date of the first documented recurrence or the last follow-up. Progression was defined as tumour recurrence at a higher stage (TNM stage $\mathrm{pTa}-1$ with increased grade, or progression from $\mathrm{pT} 1$ to $\mathrm{pT} 2$ or more) and/or transition from G1-2 to G3, histologically documented metastases or death from bladder cancer.

Progression-free intervals were defined as the time between TUR and invasive tumour growth or G3 recurrence or end of the followup period. Fisher's exact test and $\chi^{2}$ test with Yates correction were used to measure the correlation between p53 accumulation and prognostic factors. Kaplan-Meier plots and the log-rank test were used to analyse the association of p53 with the time to recurrence and with progression. Two-sided $P$-values below 0.05 were considered to be statistically significant.

The Cox proportional hazards model was used for multivariate analysis of prognostic parameters (age, sex, grade, level of invasion and p53 status). 


\section{RESULTS}

The population studied was composed of 64 women and 134 men, $34-98$ years old (mean age $=67.3 \pm 11.7$ years). There were 76 new patients consulting for symptoms possibly indicating bladder cancer and 122 patients followed up after TUR for bladder urothelial carcinoma.

There were 121 negative cystoscopy findings, 16 suspicious mucosal aspects leading to bladder biopsies and 61 typical tumour growths (Table 1). Overall, 61 bladder tumours were histologically diagnosed (27 G3 and 34 G1-2 urothelial carcinomas).

Urinary cytology was positive, high grade in 24 of 27 G3 urothelial carcinomas (sensitivity for high grade $=88.9 \%$ ) and showed tumour cells of various grades in 42 of 61 tumour cases (global sensitivity $=68.9 \%$ ), as shown in Table 2 .

The mean volume of the urine samples obtained was $50.47 \pm 57.67 \mathrm{ml}$ (range $30-200)$.

In the group demonstrating high-grade tumour cells in the urine, biopsies and TUR showed G3 urothelial carcinoma in 24 of the 32 cases with histopathological control $(75.0 \%)$. High-grade tumour cells were evidenced in eight patients with low-grade urothelial tumours, probably revealing pTIS lesions not viewed at the cystoscopy level. These cases were also positive with p53 and four of eight cases $(50.0 \%)$ recurred within a 24 -month period.

\section{p53 immunoreactivity}

LBC allowed a Thinprep ${ }^{\circledR}$ slide to be prepared for Papanicolaou staining in every case. However, after the first slide was obtained by the Thinprep ${ }^{\mathbb{R}}$ processor, the remaining material allowed a slide for p53 immunocytochemistry to be prepared in 158 out of 198 urine samples $(79.8 \%)$.

Table I Cystoscopy and histopathology data in 198 patients

\begin{tabular}{lc}
\hline Characteristic & n (\%) \\
\hline Negative cystoscopy (biopsy not performed) & $121(61.1)$ \\
Suspicious aspects in flat mucosa & $16(8.1)$ \\
Negative biopsy & $10(62.5)$ \\
Positive biopsy & $6(37.5)$ \\
PT2 G3 & 2 \\
PTIS & 4 \\
Positive cystoscopy (papillary lesions) & \\
Positive TUR & $61(30.8)$ \\
PTa GI -2 & $55(90.2)$ \\
PTa G3 & $34(61.8)$ \\
PTI G3 & $6(10.9)$ \\
$\geqslant$ PT2 & $9(16.4)$ \\
PTa G2+pTIS & $4(7.3)$ \\
Negative TUR & $2(3.6)$ \\
TUR not performed & $2(3.3)$ \\
Total & $4(6.6)$ \\
\hline
\end{tabular}

Table 2 Correlation of urinary cytology (UC) with histopathology

\begin{tabular}{lcccc}
\hline & \multicolumn{4}{c}{ Histopathology (\%) } \\
\cline { 2 - 5 } UC results & $\mathbf{G 3}$ & $\mathbf{G ~ I - 2}$ & Negative & Not performed \\
\hline Pos. high grade & $24(88.8)$ & $8(23.5)$ & - & $2(1.6)$ \\
Low grade & - & $10(29.4)$ & - & $2(1.6)$ \\
Negative & $3(11.1)$ & $16(47.1)$ & $12(100.0)$ & $121(96.8)$ \\
Total & $27(100.0)$ & $34(100.0)$ & $12(100.0)$ & $125(100.0)$ \\
\hline
\end{tabular}

The 40 remaining cases were treated as archival material: the Papanicolaou slides were destained and treated with the p53 MoAb as described in the Materials and Methods section. The expression of p53 was positive in two cases (5.0\%), negative in 18 cases $(45.0 \%)$ and unsatisfactory for evaluation in 20 cases $(50.0 \%)$ as shown in Table 3.

Positivity for p53 was assessed in 34 of 198 urinary cytology cases $(17.2 \%)$ in the whole series, including archival material in two cases. Positivity for p53 was assessed in 32 of 158 cases (20.3\%) obtained after complete Thinprep ${ }^{\circledR}$ processing.

High-grade tumours were positive for p53 in urine in 20 of 27 cases $(74.1 \%)$. All had positive, high-grade urinary cytology results.

Comparatively, low-grade (G1-2) urothelial carcinomas were positive for p53 in urine in eight of 34 cases $(23.5 \%)$, including six cases with urinary cytology findings suggesting low-grade proliferation (Figure 1).

The eight cases with low-grade urothelial tumours but positive, high-grade cytology findings showed positivity for p53 immunostaining.

Immunoreactivity for $\mathrm{p} 53$ was also tested on the tissue samples, in order to allow comparisons with other series: 22 of 27

Table 3 p53 immunostaining according to urinary cytology (UC) results

\begin{tabular}{lcccc}
\hline & \multicolumn{4}{c}{ UC results (\%) } \\
\cline { 2 - 5 } p53 status & High grade & Low grade & Negative & Total \\
\hline $\begin{array}{l}\text { Positive } \\
\quad \text { Slides for p53 }\end{array}$ & $18(52.9)$ & $6^{\mathrm{a}}(50.0)$ & $8^{\mathrm{b}}(5.3)$ & $32(16.1)$ \\
$\quad$ Destained slides & $2(5.9)$ & - & - & $2(1.0)$ \\
Negative & & & & \\
$\quad$ Slides for p53 & $10(29.4)$ & $4(33.4)$ & $80(52.6)$ & $94(47.5)$ \\
$\quad$ Destained slides & - & - & $18(11.8)$ & $18(9.1)$ \\
Not conclusive & & & & \\
$\quad$ Slides for p53 & $4(11.8)$ & $2(16.6)$ & $26(17.1)$ & $32(16.2)$ \\
$\quad$ Destained slides & - & - & $20(13.2)$ & $20(10.1)$ \\
Total & $34(100.0)$ & $12(100.0)$ & $152(100.0)$ & $198(100.0)$ \\
\hline
\end{tabular}

Including two cases without histological confirmation. 'Including two false-negative UC cases with $\mathrm{G} 3$ bladder tumours.

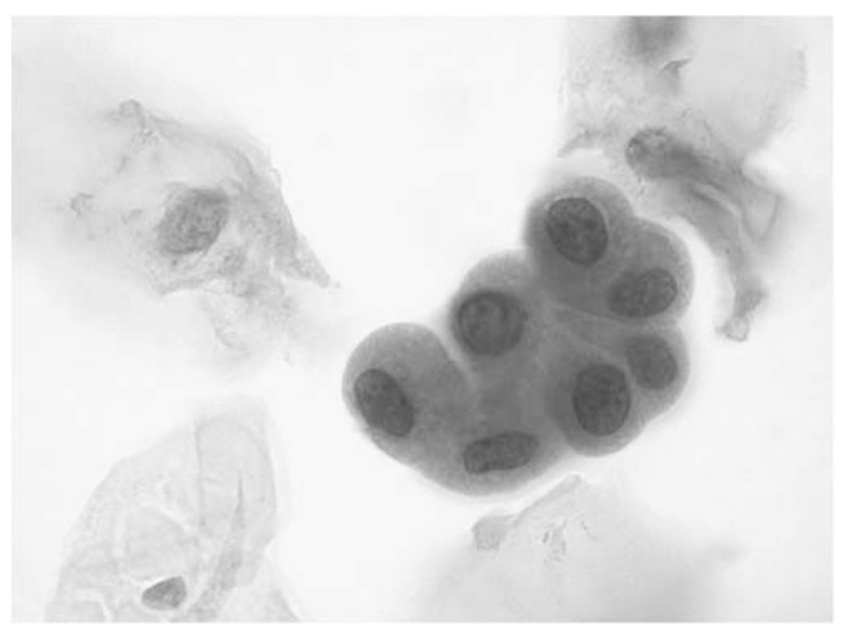

Figure I p53 immunostaining in a group of low-grade urothelial cells $(\times 400)$. 
high-grade cases (81.5\%), and 16 of 34 G1-2 tumours (47.0\%) showed positivity for $\mathrm{p} 53$. In comparison, the 12 negative tissue samples analysed were negative for p53 immunostaining.

\section{Prognostic relevance of p53 alterations in the urine}

Most patients were evaluated at $12.0 \pm 4.2$ and $24 \pm 5.6$ months after D0 (time of initial evaluation). During a median follow-up period of 26 months (range 8-42 months), 36 of 198 patients $(18.2 \%)$ had histologically proven bladder recurrence (median recurrence interval $=13.7$ months).

Recurrence was observed in 18 of 34 cases (52.9\%) with p53 overexpression, and in only 12 of 112 negative cases $(10.7 \%$, $P<0.001)$. Progression was noted in 18 of 146 valid cases $(12.3 \%)$ with a median interval of 14.2 months. Of $18(66.7 \%)$ progression cases, 12 were observed in patients with p53 positive immunolabelling.

Of $34(35.3 \%)$ bladder tumours initially recorded as low grade (pTa-1 G1-2), 12 recurred within a 24-month period (Table 4). In the same period, progression was noted in six patients including four cases positive for p53: one pT1 G2 and one pT1 G3 bladder papillary tumours with CIS were evidenced at 12 and 18 months. Two pT1 G3 bladder tumours were diagnosed at 18 and 23 months. One case was a G3 upper urinary tract tumour diagnosed at 12 months in a patient with p53 unconclusive for evaluation at D0, and there was a pT2 G3 bladder tumour diagnosed at 20 months.

In patients with high-grade tumours at D0, recurrence at 24 months was assessed in 14 of 26 cases (53.8\%) and progression was noted in 10 cases $(38.5 \%)$.

The progression rate was 12 of $34(35.3 \%)$ p53-positive cases $v s$ six of $112(5.4 \%)$ p53-negative cases $(P<0.001)$. Progression-free

Table 4 Progression according to initial histopathological data and p53 results in urine

\begin{tabular}{|c|c|c|c|c|}
\hline \multirow[b]{2}{*}{ Status at D0 } & \multirow[b]{2}{*}{ No. (\%) } & \multirow[b]{2}{*}{$\begin{array}{c}\text { Recurrence } \\
\text { at } 24 \\
\text { months }\end{array}$} & \multicolumn{2}{|c|}{ Progression (\%) } \\
\hline & & & $\begin{array}{c}12 \\
\text { months }\end{array}$ & $\begin{array}{c}24 \\
\text { months }\end{array}$ \\
\hline $\begin{array}{l}\text { GI-2 bladder } \\
\text { tumours }\end{array}$ & $34(17.2)$ & $12(35.3)$ & - & - \\
\hline p53 positive & $8(23.5)$ & $6(75.0)$ & 0 & $4(50.0)$ \\
\hline p53 negative & $8(23.5)$ & $2(25.0)$ & 0 & 0 \\
\hline p53 uc & $18(53.0)$ & $4(22.2)$ & $2(11.1)$ & 0 \\
\hline $\begin{array}{l}\text { G3 bladder } \\
\text { tumours }\end{array}$ & $27(13.6)$ & $14(51.9)$ & - & - \\
\hline p53 positive & $20(76.9)$ & $10(50.0)$ & $4(20.0)$ & $4(20.0)$ \\
\hline p53 negative & $6(23.1)$ & $4(66.7)$ & 0 & $2(33.3)$ \\
\hline p53 uс & 0 & - & - & - \\
\hline Negative & $12(6.1)$ & 0 & - & 一 \\
\hline $\begin{array}{l}\text { histology } \\
\text { p53 positive }\end{array}$ & 0 & 0 & - & - \\
\hline p53 negative & $12(100.0)$ & 0 & $0(\bar{l} \mathrm{nr})$ & $0(\mathrm{I} n \mathrm{r})$ \\
\hline p53 uc & 0 & 0 & - & - \\
\hline No histology & $125(63.1)$ & $10(8.0)$ & - & - \\
\hline p53 positive & $6(4.8)$ & $2(33.3)$ & $0(\mathrm{lnr})$ & $2(33.3)$ \\
\hline p53 negative & 84 (66.7) & $6(7.1)$ & $4(17 \mathrm{nr})$ & $0(25 \mathrm{nr})$ \\
\hline p53 uc & $34(26.9)$ & $2(5.9)$ & 0 & $2(5.8)$ \\
\hline Cumulated data & $198(100.0)$ & $36(18.2)$ & - & - \\
\hline p53 positive & $34(17.2)$ & $18(52.9)$ & - & $12(35.3)$ \\
\hline p53 negative & $112(56.6)$ & $12(10.7)$ & - & $6(5.4)$ \\
\hline p53 uc & $52(26.2)$ & $6(11.5)$ & - & $6(11.5)$ \\
\hline
\end{tabular}

$\mathrm{uc}=$ unconclusive for evaluation; $\mathrm{nr}=$ patient not reviewed.

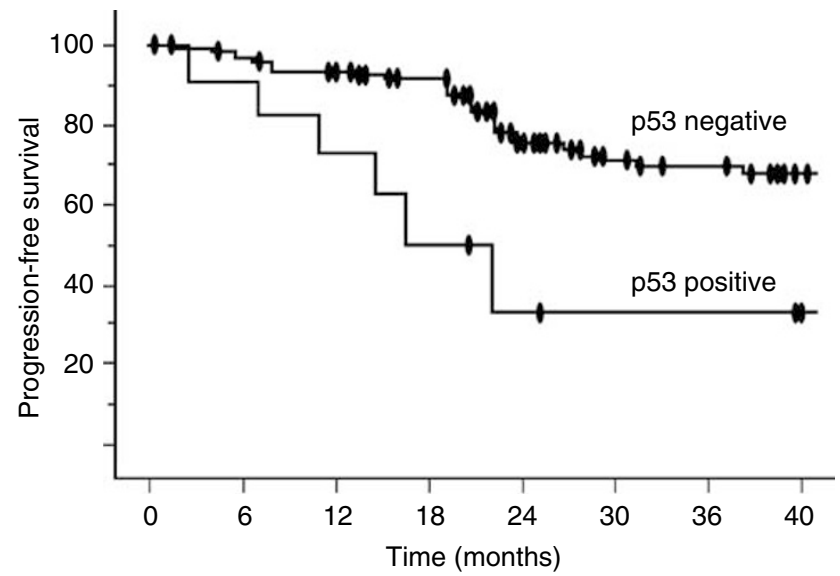

Figure 2 Kaplan-Meier progression-free survival curves in patients with p53-negative and p53-positive urine samples $(P=0.007)$.

survival was significantly shorter in patients with p53 accumulation in voided urothelial cells $(P=0.007$, log-rank test, Figure 2$)$.

In a multivariate analysis, p53 was an independent predictor of overall survival $(P=0.042)$ when compared with age $(P=0.898)$, sex $(P=0.996)$ grade $(P=0.097)$ and level of invasion $(P=0.750)$.

\section{DISCUSSION}

p53 is located on chromosome $17 \mathrm{p} 13$. The p53 gene is mutated in about $50 \%$ of human cancers, and nuclear accumulation of p53 protein demonstrated by immunohistochemistry is recognised as an independent prognostic factor for disease progression in most studies (Olumi, 2000). Most patients with allelic loss of 17p or p53 mutation have positive p53 immunoreactivity, as well as patients with LOH of the p16 locus located on 9p21 (Sourvinos et al, 2001). However, it has been shown that a fraction of patients with p53 overexpression has no genetic alterations, but has functional defects in the cell cycle regulation (Friedrich et al, 2001).

In bladder tumours, a number of studies have shown a positive correlation between p53 overexpression and mutation detection by DNA sequencing (Stadler et al, 2001; Hopman et al, 2002). However, p53 nuclear accumulation in the absence of gene mutation has also been noted.

The first studies of p53 alterations in the urine used a cloning approach followed by sequencing to confirm the presence of mutations (Sidransky et al, 1991). Thereafter, several reports have compared mutations in tissue samples with those found in the urine: p53 gene mutation in the urine has been shown to correlate with tumour recurrence or residual (Sachs et al, 2000). Voided urine specimens and bladder wash specimens have $>90 \%$ accuracy in detecting p53 mutations compared with tumour tissue and show the same mutations after sequencing (Prescott et al, 2001).

Some authors have shown that a number of microsatellite alterations on p16, p53 and RB1 regions found in cytological urine specimens were not detectable in the corresponding tumour biopsies (Sourvinos et al, 2001). Such discrepancies suggest exfoliation of aggressive cell clones not sampled by biopsies, that is, originating from CIS areas better detected in cytological analysis.

However, only a few studies have been devoted to voided urine specimens, probably because attempts to use p53 as a diagnostic marker in urine have shown relatively low values (Righi et al, 1997). In the Righi series, the $23.5 \%$ sensitivity and $75 \%$ specificity reported render p53 less attractive than conventional urinary cytology for diagnosing bladder cancer. 
Very few tumour markers (including Ki-67, uCyt + and p53) have been recognised as having a prognostic impact in bladder urine specimens: a Ki-67 index over $20 \%$ may predict those pTa-1 G1 - 2 tumours that are likely to recur within 1 year of treatment (Gontero et al, 2000). Patients followed after TUR recur in $50 \%$ of cases when they have a positive uCyt + assay despite negative cystoscopy in the year following urinary tests (Piaton et al, 2003).

In the literature, data on the prognostic value of p53 are controversial. The relevance of p53 in muscle-invasive, pT1 G3 bladder tumours is well documented, but the prognostic impact of p53 alterations in superficial, low-grade tumours remains uncertain (Friedrich et al, 2001; Wolf et al, 2001). Although some groups have shown that p53 is a significant predictor of bladder tumour progression (Schmitz-Dräger et al, 2000), others have concluded that it provides no prognostic information (Gontero et al, 2000; Friedrich et al, 2001).

There are a number of possible explanations for these contradictory results: first, some studies are based on small numbers of patients with various treatment modalities. Second, differences between laboratories may be related to the choice of p53 antibody, labelling protocol and scoring criteria. As stressed by SchmitzDräger et al (2000), standardisation of p53 immunolabelling is a matter of primary interest.

There is evidence that interactions between the antibody and the tissue might influence the outcome of the assay: p53 can be modified by phosphorylation (or acetylation/ubiquitination) at several sites, and the consequences of such phosphorylation for p53 function and epitope masking are still very poorly understood. DO-7, like DO-1, is sensitive to serine 20 phosphorylation, and this might underestimate the sensitivity of the assay (Dumaz et al, 2001). However, this aspect is never really discussed in review articles on p53 immunochemistry.

Although some studies have addressed the detection of mutated p53 in urine, none to our knowledge has studied the impact of LBC processing on p53 immunoreactivity. In the present series, LBC allowed a slide for p53 immunocytochemistry to be prepared in $79.8 \%$ of cases, and positivity for p53 was assessed in 32 of 34 cases (94.1\%) after treatment by the Thinprep ${ }^{\circledR}$ processor.

In our opinion, the good results obtained are due to LBC technical improvements that allow pre-immunolabelling procedures to be standardised. In solid tumours such as in breast carcinomas, other authors have demonstrated that Thinprep ${ }^{\mathbb{R}}$. processed samples allowed efficient DNA, RNA and protein recovery (Tisserand et al, 2003). In addition to improvements due to software-assisted filtration, the Thinprep ${ }^{\circledR}$ method allows unprocessed samples to be stored into the PreservCyt ${ }^{\mathbb{R}}$ solution, which maintains DNA, RNA and proteins suitable for molecular analyses even after several months of storage at $4^{\circ} \mathrm{C}$ or at $-20^{\circ} \mathrm{C}$ (Tisserand et al, 2003).

In our series, p53 was positive in the urine in $46.7 \%$ of the tumour cases, and in $76.9 \%$ of the high-grade bladder tumours. Only $5.3 \%$ of cytologically negative cases were found p53 positive. Our results are comparable to those of Prescott et al (2001) in which 19 of $49(38.8 \%)$ histologically confirmed tumours would have been detected by p53. However, no p53 mutation was detected in their negative cases.

More importantly, recurrence was observed in $52.9 \%$ of our cases with p53 overexpression, and progression was noted in $12.3 \%$ of the patients, $66.7 \%$ of progression cases being observed in patients with p53-positive immunolabelling. In the low-grade group, it is important to know whether p53 overexpression is linked to prognosis. From our results, in spite of the low number of patients, it is interesting to note that among eight cases with G1 - 2 bladder tumour and p53 positive in the urine, six $(75.0 \%)$ have recurred and four (50.0\%) have progressed within a 24month period (Table 4).

Both data illustrate that p53 mutation detection has limited clinical utility for the detection of bladder tumours, but that voided urine specimens provide a good material for studying p53 in a prognostic attempt. Our results, combined with those of Tisserand et al (2003) obtained on cell lines and on breast cancer cells, show that Thinprep ${ }^{\mathbb{R}}$ LBC provides a very good material for molecular analysis, and that it could be considered as a technical standard for cytology-based molecular studies.

We conclude that owing to its negative impact on survival as demonstrated in this study, p53 in the urine might do more than play a simple role in identifying bladder tumour cases that may progress from superficial to invasive disease.

\section{ACKNOWLEDGEMENTS}

We thank J Boulon for her help in manuscript preparation. The technical component of the study was supported by Cytyc (Cytyc Corporation, Boxborough, MA, USA) and the immunologic reagents were supplied by DAKO (DAKO S.A., 78196 Trappes Cedex, France).

\section{REFERENCES}

Anagnostopoulou I, Spathi H, Rammou-Kinnia R, Karakitsos P, Gianni I, Georgoulakis J, Kittas C (2000) Comparative study of Thinprep and conventional voided urine cytology (Abstract). Cytopathology 11: 373

Bastacky S, Ibrahim S, Wilczinski SP, Murphy WM (1999) The accuracy of urinary cytology in daily practice. Cancer (Cancer Cytopathol) 87: $118-128$

Brandau S, Böhle A (2001) Bladder cancer I. Molecular and genetic basis of carcinogenesis. Eur Urol 39: 491-497

Dumaz N, Milne DM, Jardine LJ, Meek DW (2001) Critical roles for the serine 20 , but not the serine 15 , phosphorylation site and for the polyproline domain in regulating p53 turnover. Biochem J 359: 459-464

Epstein JI, Amin MB, Reuter VR, Mostofi FK, the Bladder Consensus Conference Committee (1998) The World Health Organization/International Society of Urological Pathology Consensus Classification of urothelial (transitional cell) neoplasms of the urinary bladder. Am J Surg Pathol 22: 1435-1448

Friedrich MG, Riethdorf S, Erbersdobler A, Tiemer C, Schwaibold H, Sölter JK, Huland E, Riethdorf L, Conrad S, Hammerer PG, Huland H (2001) Relevance of p53 gene alterations for tumour recurrence in patients with superficial transitional cell carcinoma of the bladder. Eur Urol 39: 159-166
Gontero P, Casetta G, Zitella A, Ballario R, Pacchioni D, Magnani C, Muir GH, Tizzani A (2000) Evaluation of p53 protein overexpression, Ki-67 proliferative activity and mitotic index as markers of tumour recurrence in superficial transitional cell carcinoma of the bladder. Eur Urol 38: $287-296$

Hopman AH, Kamps MA, Speel EJ, Schapers RF, Sauter G, Ramaekers FC (2002) Identification of chromosome 9 alterations and p53 accumulation in isolated carcinoma in situ of the urinary bladder versus carcinoma in situ associated with carcinoma. Am J Pathol 161: $1119-1125$

Murphy WM (1990) Current status of urinary cytology in the evaluation of bladder neoplasms. Hum Pathol 21: 886-896

Olumi AF (2000) A critical analysis of the use of p53 as a marker for management of bladder cancer. Urol Clin N Am 27: 75-82

Piaton E, Daniel L, Verriele V, Dalifard I, Zimmermann U, Renaudin K, Gobet F, Caratero A, Desvaux D, Pouille Y, Seigneurin D, the urologists participating in the uCyt+ Trial (2003) Improved detection of urothelial carcinomas with fluorescence immunocytochemistry (uCyt+ assay) and urinary cytology: results of a French Prospective Multicenter Study. Lab Invest 83: $845-852$ 
Piaton E, Faÿnel J, Ranchin MC, Hutin K (2002) Comparative study of conventional techniques and liquid-based processing of urine samples for the evaluation of bladder neoplasms (Abstract). Acta Cytol 46: 207

Piaton E, Faÿnel J, Ranchin MC, Hutin K, Cottier M (2004) Cost-efficiency analysis of modern cytocentrifugation methods versus liquid-based (Cytyc Thinprep*) processing of urinary samples. J Clin Pathol 57: 1208-1212

Prescott JL, Montie J, Pugh TW, McHugh T, Veltri RW (2001) Clinical sensitivity of p53 mutation detection in matched bladder tumour, bladder wash, and voided urine specimens. Cancer 91: 2127-2135

Righi E, Rossi RE, Ferrari G, Dotti A, De Gaetani C, Ferrari P, Trentini GP (1997) Does p53 immunostaining improve diagnostic accuracy in urine cytology? Diagn Cytopathol 17: 436-439

Saad A, Hanbury DC, McNicholas TA, Boustead GB, Woodman AC (2001) The early detection and diagnosis of bladder cancer: a critical review of the options. Eur Urol 39: 619-633

Sachs MD, Schlechte H, Lenk VS, Brenner S, Shnorr D, Fleige B, Ditscherlein G, Loening SA (2000) Genetic analysis of Tp53 from urine sediment as a tool for diagnosing recurrence and residual of bladder carcinoma. Eur Urol 38: 426-433

Schmitz-Dräger BJ, Goebell PJ, Ebert T, Fradet Y (2000) p53 immunohistochemistry as a prognostic marker in bladder cancer. Eur Urol 38: 691-700
Sidransky D, Von Eschenbach A, Tsai YC, Jones P, Summerhayes I, Marshall F, Paul M, Green P, Hamilton SR, Frost P, Vogelstein B (1991) Identification of p53 gene mutations in bladder cancers and urine samples. Science 252: 706-709

Sourvinos G, Kazanis I, Delakas D, Cranidis A, Spandidos DA (2001) Genetic detection of bladder cancer by microsatellite analysis of p16, RB1 and p53 tumour suppressor genes. J Urol 165: 249-252

Stadler WM, Steinberg G, Ynag X, Hagos F, Turner C, Opolade OI (2001) Alterations of the 9p21 and 9q13 chromosomal bands in clinical bladder cancer specimens by fluorescence in situ hybridization. Clin Cancer Res 6: $1676-1682$

Tisserand P, Fouquet C, Marck V, Mallard C, Fabre M, Vielh P, Soussi T (2003) Thinprep-processed fine-needle samples of breast are effective material for RNA- and DNA-based molecular diagnosis. Application to p53 mutation analysis. Cancer (Cancer Cytopathol) 99: $223-232$

Wolf HK, Stöber C, Hohenfellner R, Leissner J (2001) Prognostic value of p53, p21/WAF1, Bcl-2, Bax, Bak and Ki-67 immunoreactivity in pT1 G3 urothelial bladder carcinomas. Tumour Biol 22: 328-336

Wright RG, Halford JA (2001) Evaluation of thin-layer methods in urine cytology. Cytopathology 12: 306-313 